\title{
PROBLEMS OF CONTENT PRODUCTION IN REGIONAL MASS MEDIA
}

\author{
Sandra Murinska \\ Rezekne Academy of Technologies, Latvia
}

\begin{abstract}
This article examines problems and importance of content production in regional information space. This is an emerging question within a rapidly restructuring media landscape, and globalized information flows with aim to manipulate and destroy democratic order. Policy guidelines for Latvian media 2016 - 2020 describes five steps how to fight against these hazards. One of the steps are the strengthening of local information area and facilitating media pluralism, many tasks are dedicate to support regional media, realizing media fund programs with aim to ensure the availability of information for people in the regions.

Regional journalism is classified as unexplored field of research, especially in Latvia, there is a lack of researches about how local journalism should work and what are their working strategies and problems.

This article analysis data of survey made among local journalists about their content production practices. The aim was to explore a) what are criteria for content production and selection of news, b) what kind of information is making local information space, c) what are the threats for journalism in regions. Respondents were local journalists in Latgale region of Latvia working in local newspapers, radio and television.

Results encountered a very strong attachment to local community and identity construction not to so much dealing with journalistic mission and techniques.
\end{abstract}

Keywords: content productions, local journalism, regional journalism, hyperlocal news, media usage, community integration.

\section{Introduction}

It seems in the 21st century is quite unpopular to talk about regional (or local) media, where the dynamics of communication and opportunities created by social media is dominating over society. Often these conditions are referred as a threat to regional and local media. This kind of media, which mainly focuses on geographically limited spatial representation of events, is looking for ways to continue to exist - within help of private investors as well as the state assistance. So called "big themes", global communication - these are features you can`t find in regional journalism. Still it is important source of information in a particular environment.

Adjunct Professor of Journalism Studies at the University of South Australia Ian Richards explains idea of local news researcher Kannis who already in the 
beginning of 90ties found "that local news is anything but inconsequential and that the news media "produce local identity as much as they produce news" (Kannis, 1991, cited from Richards, 2012).

In Europe, countries with strong mass media traditions regional journalism, for example, printed press is described as opposite to capital or big journalism. "Even in countries like Germany - with a still 'healthy' local news market, local papers with high circulation, and a majority of professional journalists working in this field - local news tends to be seen as secondary to the national print and broadcasting sector in terms of quality and status”, (Harnischmacher, 2014). The situation is similar in science as well. "Local news' has certainly not been among the prime research subjects in our field in the past decade. In fact, it appears to be a kind of neglected stepchild of both journalism and journalism research" (Harnischmacher, 2014).

In much of the literature such journalism is presented as "merely a "smaller" version of the journalism practised in major cities with few, if any, distinguishing characteristics beyond the size and scope of its audience' (Bowd, 2010: 2). Although this journalistic status is assessed as insignificant in the global communication, however, regions, it exists and is part of the information spaces builders. In much of the literature, too, there is a lack of clarity around concepts such as 'local' and 'community' which are central to understanding rural and regional journalism. Yet the importance of such journalism has been apparent for years (Richards, 2012). Regional media is an important urban and regional operating practices, in order to inform the public of what is happening here is the neighbor's house, which is or is not doing, who is not responsible for its promises, government to ask for help, etc.

Since its inception, the local media, particularly newspapers, have had to take on the role of local watchdogs for communities. These media and journalists are close to their community, they have similar aims, and they understand audiences, their needs, interests and desires. Moreover, the most important thing - it is a message that is not reflected only in the local medium. However, local media environment also shows the involved parties when operating and / or affect the media. Also, the content of each of the journalistic methods and techniques differ. Especially in the era of new media which is counted as changing environment. Local media researcher Michael Harnischmacher says ,there are worries about the diminishing role of traditional journalism or, more precisely, traditional journalistic virtues in the process of content production and one of those forces in many countries is the intrusion of alternative news websites on a local level, which are challenging newspapers' monopoly on local and regional information" (Harnischmacher, 2014).

Consequently, local and regional journalism environment raises questions about the principles, values and thus content building trends. The question is, of 
course, not restricted exclusively to local journalism, it is a vital problem for journalism in general. The main purpose of this article is to state problems faced in local journalism in content creation process in region of Latgale a) what are criteria for content production and selection of news, $b$ ) what kind of information is making local information space and c) what are the threats for journalism in regions. The questionnaire and qualitative interviews was make to investigate opinion of local journalists point of view in Latgale region of Latvia.

\section{Theoretical issues: the role of local media}

Taking into account the diverse range of mass communication means, especially the electronic ones, local print media still plays a significant role in people's everyday life, even though local media has a marginal role in the theoretical literature and science in general.

Researchers in nowadays are worried about the changing nature of journalism in the era new media environment. There are worries about the diminishing role of traditional journalism or, more precisely, traditional journalistic virtues in the process of content production (Harnischmacher, 2014). Looking on the existing researches in local and regional media field, it looks it is one of the stable journalism practice because of its location and functions in the community. Researchers emphasize local journalism as a mediator because it joins the regional and the national: "Local and regional newspapers seem to specialize in local journalism, i.e. they cultivate local journalism as a niche product for local audiences and advertisers. Further, there is evidence that these media are important communication channels for local as well as national political actors” (Skogerbø \& Winsvold, 2011). Studies of theoretical literature show that the role and functions of local media are mainly related to the link between identity and journalism and the local community. Although the importance of the features mentioned above cannot be questioned, each cultural and social environment has its own difference in practice, because it is affected by media policy, economic conditions, technological options, etc. As Coxon says "since the early 2000s, the media has become driven primarily by its own (commercial) interests and is now more an author than a mediator of culture" (Coxon, 2017). The importance of community news is attributed to the two processes it can (and should) facilitate: (1) revealing the social structure to the residents and (2) cultivating a collective sense of belonging and a cohesive set of identities by providing discursive resources for the symbolic construction of community (Janowitz, 1967 [1952]; Lowrey et al., 2008). Results of the study that explored the role of local media in facilitating community communication and understanding, and, through this, to shed light on their possible contribution to 
regional social capital in Australia (Richards, 2014) concluded, "local media facilitate communication between journalists and non-journalists to the benefit of the local community. In each region, local people rely on "their" media for news and information about local happenings and assume that this news and information will be presented in ways which support the common interests of the region. For their part, local journalists rely on local people to let them know of matters, which can be published, or broadcast, and to inform them of the context in which these matters have developed. What enters the public arena through the local media as a result of this reciprocal relationship was considered by all to be different from the content typically provided by larger metropolitan or national media”. Author reminds about one of the central value of journalism - it is community building, by publishing material which elicits empathy, admiration or pride in others' achievements, journalists can enhance the bond that joins people together as a society (Richards, 2014), through the emphasis on common values rather than on the solution of conflicting values. Thus local media are making network around itself.

Still, in some local markets, the traditional local press faces a new competitive environment. Contemporary changes in local media are tied with a wider change in the way in which we live our lives, the way in which the economy works, and the way in which politics works (Nielsen, 2015). In addition to the websites of the legacy media, independently produced news sites can be found, with a wide array of appearances from weblogs to community-based forums to semiprofessional and professional online 'newspapers' (Harnischmacher, 2014). It could come one of the challenges for traditional local media market and is called a hyperlocal media that operates in Web 2.0 environment, using different journalistic genres and sources and making concrete social organization. It makes concrete audience as well. For example, local news websites content are made both of journalists and reader's content, which is typical community network making hyperlocal news. As in this research local website representatives were included in survey, it is noteworthy to pay attention to such occurrence.

Such way of information space construction and content production has been described as hyperlocal. Rather than dwelling on its typology, the term 'hyperlocal' is used as a metonym to signify the focal tensions around its relationship with the community and its civic function (Zhang, 2017). Hyperlocal media have been described as "a hybrid of civic, community, statewide public affairs, and alternative newspaper movements combined with the interactive and broadcast abilities accompanying Web 2.0" (Dickens, Couldry, \& Fotopoulou, 2015). There are made several reseraches to explore and concept and expression of hyperlocal news in local communities because it`s potential to reach and activate community: analysed the relationship between local storytelling and civic engagement: when local stories are missing from mainstream media, or existing 
publications fail to talk about the collective problems of a specific community or neighbourhood, Web-based storytelling platforms can enhance civic engagement and inter-group interaction (Dickens, Couldry, \& Fotopoulou, 2015). This activity could be described with human geographer Tuan`s conception. He posits that two elements construct this notion of attachment to urban environments: public symbols (prominent landmarks or monuments) and fields of care, or 'networks of interpersonal concern' (Tuan, cited in Boyles, 2016). Fields of care exist when urban residents possess emotional ties and/or attachment to geographic space and when citizens are vocally aware of this sensing and/or spatial connection (Boyles, 2016). Definitely, mass media is very important tool to make emotional ties. It is a way to be acquainted with local environment. Researchers argues that "today's new media products - particularly blogs and hyperlocal websites - continue to 'stimulate our appetite for consuming the local'. Further examination of digital news production and its ability to establish fields of care stand essential to understanding how social identity is established in urban space, as well as how news organizations can better connect with their local audiences, who are increasingly difficult to reach (Zukin, 2009; Boyles, 2016).

Hyperlocal movements and activities can make impact on local media environment, because they become competitive force for local journalists or on the contrary to make them aware of emerging competition. But it is a one of they ways to realize main local media functions, because the assumed mechanism is premised on the model of watchdog journalism and citizen participation, substantiated in hyperlocal's enhanced capacity to create and consume hyperlocal content and facilitate engagement with local affairs and community formation through interaction online. Together, the emphasis is on informing, monitoring, and participation (Zhang, 2017). Nowadays it is a vital question because many of people are leaving regional territories for socio-economic conditions but such way of communication let them stay integrated into local community. The concept hyperlocal is becoming as a part of local communication environment and some of communication channels already use this type of journalistic practice, for example, local news websites who accepts and stresses some civic activity.

Nevertheless, Director of Research at the Reuters Institute for the Study of Journalism Dr. Rasmus Kleis Nielsen emphasizes "People everywhere rely on wide and diverse media repertoires to be entertained and stay informed. But when it comes to local news, local newspapers have historically played a central role" (Nielsen, 2015). It means traditional media still is important source of local news. And in regional areas in Latvia local newspapers are one of the most common mean of mass communication but as in many countries they "Are under tremendous pressure today" (Nielsen, 2015). By this paper author tries to state problems local media is faced. 


\section{Methodology}

This questionnaire covered four thematic areas: content (such as thematic selection, news values, and research principles), identity (such as professional roles, self-evaluation), tendencies in the last year and plans for the future.

There are 20 journalists participated in the survey, they were representatives from local newspapers, radio and television. There should be pointed that most of respondents were journalists of local newspapers (75 \%) as it is one of the most popular type of local media in media market. The average age of participants 36,3 and the most of them were women (85 \%). For each question, there could be more answers.

To become acquainted with the new emerging communication tool in regional space qualitative interviews (4) were made with local website editors to get deeper inside in this novel way of information production for local community. It was interesting that majority of doesn't feel like doing journalistic work and although they are working with content production and realize a lot of journalism functions and tasks.

The region of Latgale is object of this research because of its geographic position and situation in mass media space which is characterized one who has two information spaces. The Sub-programme "Information Space of Latgale" of the Transport and Communications Programme "Connections") is developed in the The Action Programme "Latgale Programme 2010-2017". Several actions are mention in The Mass Media Policy Guidelines of Latvia 2016-2020 to strengthen the public service media, which includes increase in the proportion of original content there in. The Plan also includes activities to restrict illegal distribution of electronic mass media content (including in the border area of Russia) and to increase the ability to implement the supervisory function of the NEMMC - which is directed towards in creasing the securitability of the mass media environment of the whole Latvia, inter alia of Latgale (The Mass Media Policy Guidelines of Latvia 2016-2020, 2016).

\section{Findings and discussion}

The last paragraph will highlight results from both the interviews and the survey. The focus of the analysis presented here is to determine whether regional journalism feel changes in journalism, mentioned in theoretical part, for example, the impact of new media and what are the tendencies in content production process and do regional journalists are making qualitative journalism.

It is clearly seen that results of survey shows findings based in theoretical issues. Journalists working in local media highlights aspects of belonging, main mass communication functions and strong relationships with community. As a 
primary function of local media, respondents see strengthening of regional identity. The second most mentioned answers were to educate, to inform about actualities and to defend interests of community. As it is seen the very strong tendency is to inform community, to see what respondents understand by informative functions there were included two provocative answers - to inform about problems and to inform about actualities. It shows distinct feature of regional journalism - to highlight positive events happening in community not so concentrate on local problems. Thus, it is a bit controversial because the answer to defend interests of community apply to understanding of local community problems. Anyway, regional identity is easier to raise emphasized pleasant activities. Richards mentions one of the biggest problem for local journalists, "Unlike most media in large urban centers, local journalists often develop a world view which they share with those whose activities they report, a world view which revolves around the core aim of promoting the common good of the community. This situation raises some important questions about the role and nature of regional journalism” (Richards, 2012).

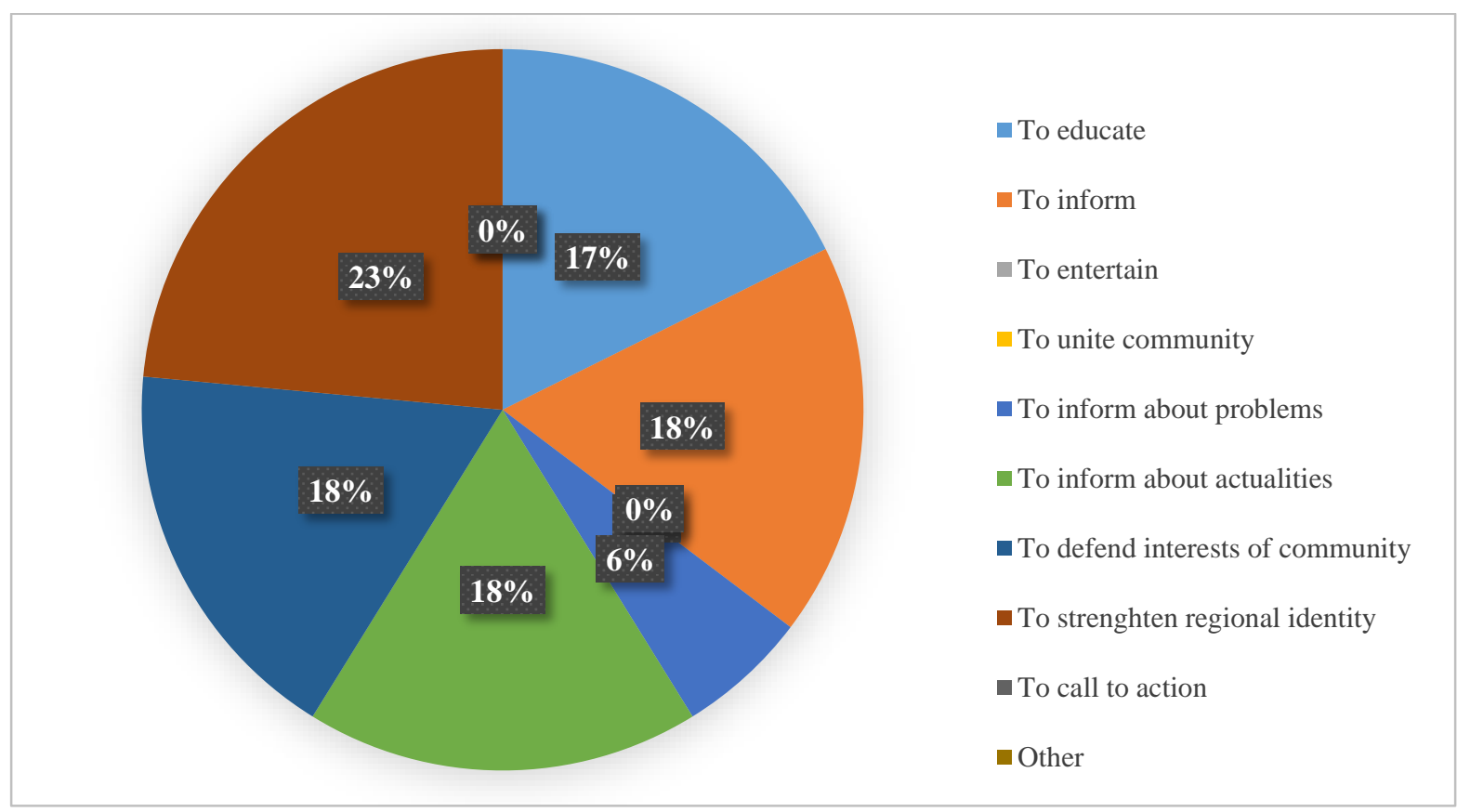

Figure 1. Functions of the local media

The tendency shows the most important thematic areas or topics journalists as well. So-called "hard" news (politics and economics) are in the end of the list, the most popular are topics culture, social topics and education. Education is characterized as soft news because this topic gives a lot of information for content production, as schools are one of the center of local community. Especially in those communities of less amount of people. Local media are more cautious and 
softer in it`s expressions, they don `t highligtht so much negative things and try to maket ties to local community or local place by using personification and personalization. Conclusion confirms opinion of media researcher Janowitch more than 50 years ago, that „Under the framework of community integration, the principal role of the community news was "to maintain local consensus through the emphasis on common values rather than on the solution of conflicting values" (Janowitz, 1967). This is confirmed by answers on the question about threats to mass media. Journalists answered, first, it is a lack of audience and educated journalists, and the second, it is a presence of news websites. The results pointed toward an emphasis on informative and identity construction function.

\section{Journalistic formats and sources}

The results of used sources for content producing showed that in most of cases is press releases and Internet. It means Internet as a source is important for printed as well as for electronic media. Relying on the Internet materials, critical thinking skills should be very developed.

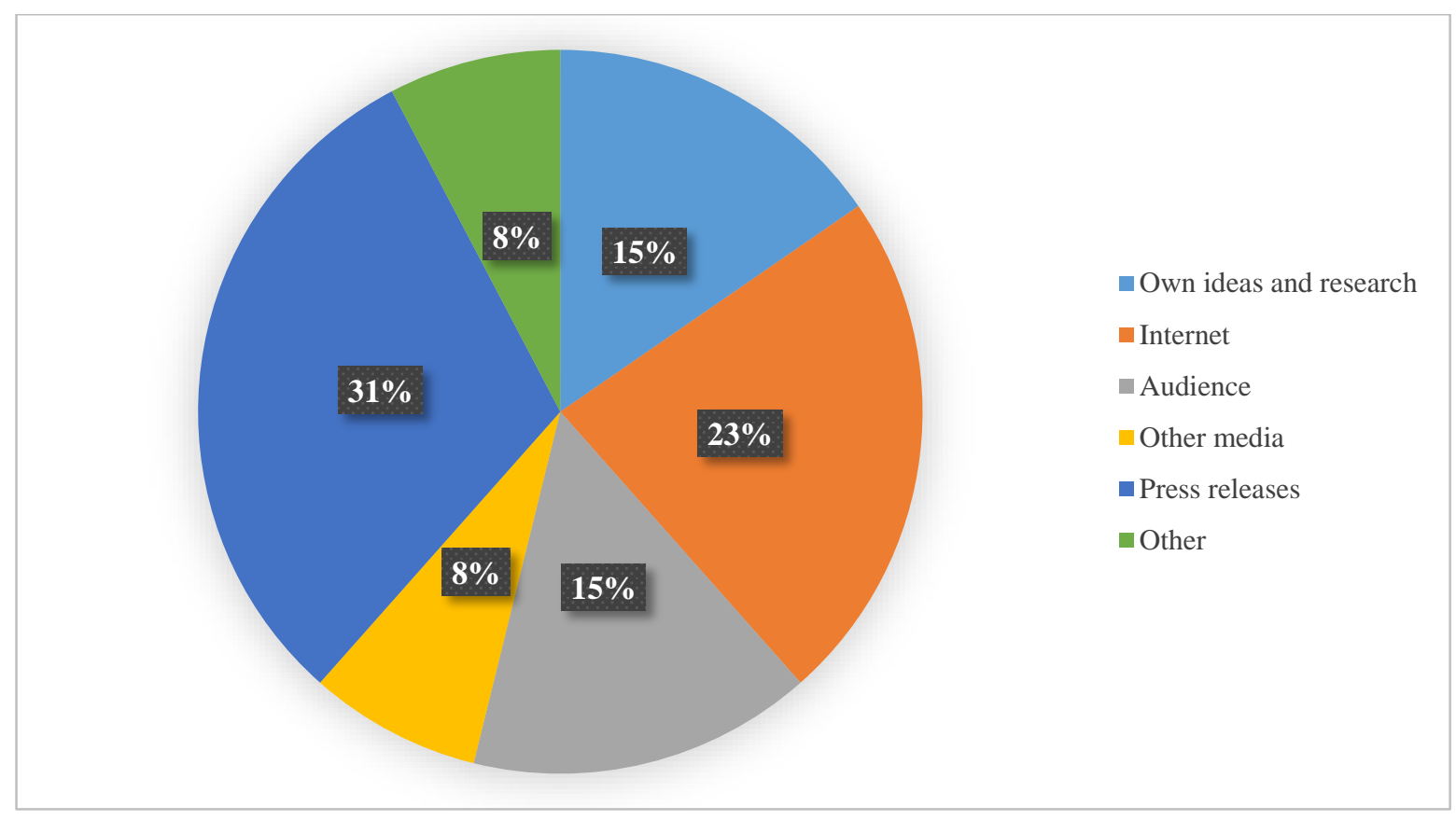

Figure 2. Use of sources by local journalists

The answer other (event organizers and local people call and report on happenings) shows that still those are already made news not originally made articles with comments and opinions. The third and fourth most popular are the own ideas and audience requests. Other media has a less role in producing stories.

Results of most popular genres (Figure 3) for regional mass media showed that running commentary and interview are amongst popular. It means that 
content is formed by sources opinion and interpretation not so much on journalists analysis. Other genres have less meaning in content creation process.

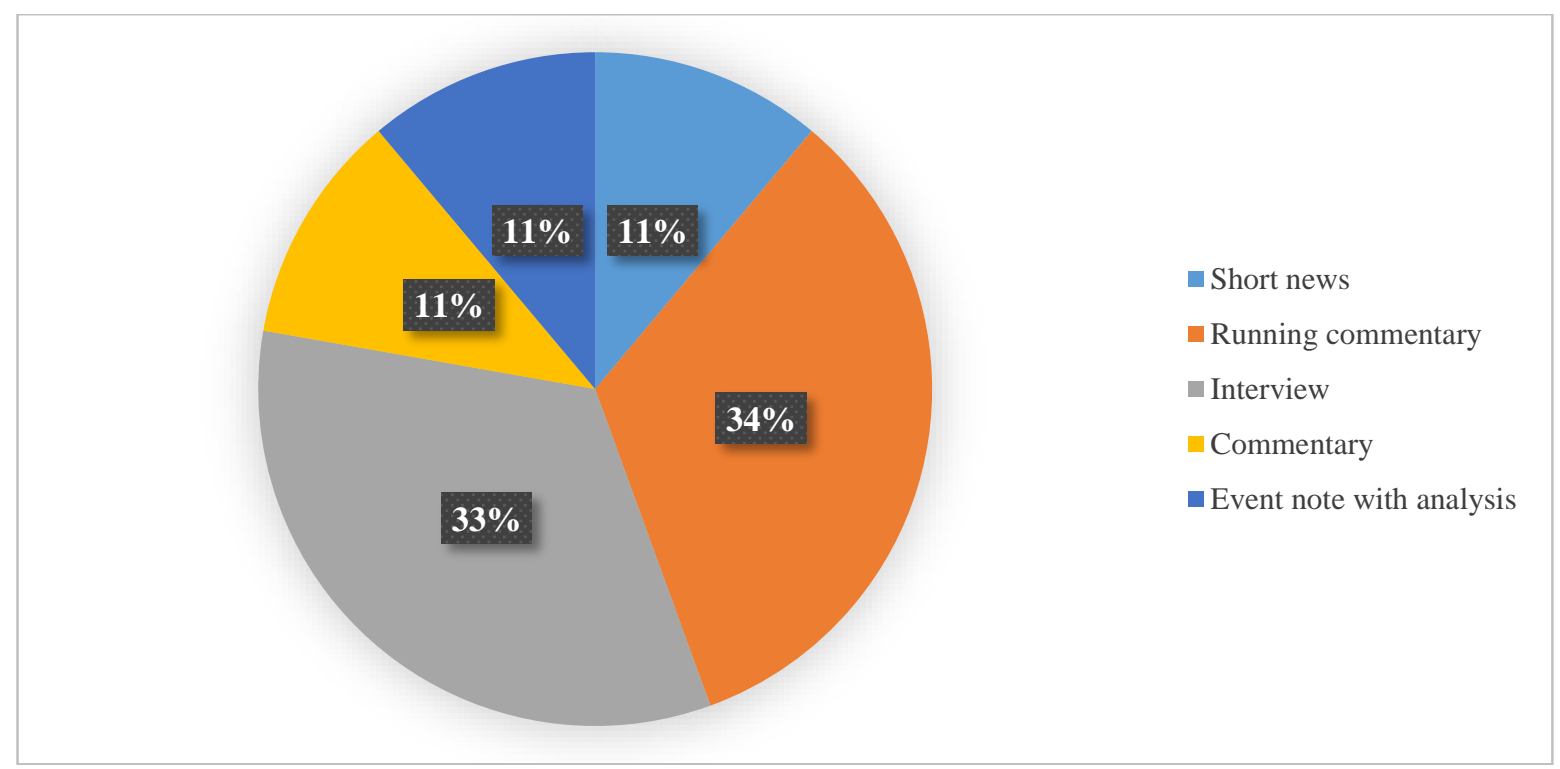

Figure 3. Journalistic genres in local media

For journalists it is important that local community can do personalization with events and people mentioned in the media content. It is the first answer what characterizes production of local content. Local relevance and proximity as well as positive information is mentioned as the second condition.

Asking do they see themselves as creative persons, the most of respondents answered that they agree (50 \%) and more agree (50\%), no one chose answer don `t agree. The question, if they are critical to their sources, journalist's answers were contrary. Most of them more agree that agree, but still $25 \%$ answered that rather disagree, and all of respondents agree they can influence public opinion. Journalists themselves characterizes as relevant occupation. $75 \%$ respondents more agree it is a prestige profession.

Results showed content production in regional media is focused on positive community evaluation not so much on development of new ways of reaching audience, for example, using digital distributing platforms or methods of information representation. Thus the question how to make qualitative information space and what is the future for regional journalism in much cases relies on national or public media. Thus, there is still lack of qualitative journalism and realization of local media functions - to be a watchdog and take care about local community. Probably this function will be taken by so-called hyperlocal websites that is growing phenomenon in regional information space and made by local journalists and partly by users. For example, some of newspapers are already doing that. The newspaper website is becoming a place where community can 
actively participate as commentators realizing function of sources for content creation. The exploration of the local websites will be the next step in the research of content production in Latgale, as it is concluded that existing local media can strengthen local media space working mainly for identity construction. There are major doubts whether it is sufficient to strengthen information space.

\section{References}

Boyles, J. L. (2016). Building an audience, bonding a city: digital news production as a field of care. Media, Culture \& Society, 39, 7, 945-959.

Coxon, K. (2017). Attention, Emotion, and Desire in the Age of Social Media. In Prado, C., G. Khadija Coxon. Social media and your Brain. Web-Based Communication is changing how we think and express ourselves (49). Santa Barbara, Calfornia: Praeger.

Dickens, L., Couldry, N., \& Fotopoulou, A. (2015). News in the community?, Journalism Studies, 16, 97-114.

Skogerbø, E., \& Winsvold, M. (2011). Audiences on the move? Use and assessment of local print and online newspapers. European Journal of Communication, 26, 216.

Harnischmacher, M. (2014). Journalism After All: Professionalism, content and performance A comparison between alternative news websites and websites of traditional newspapers in German local media markets. Journalism, 16, 1062-1064.

Janowitz, M. (1967). The Community Press. Chicago, IL: University of Chicago Press.Kanniss P. (1991) Making Local News. Chicago, IL: University of Chicago Press.

Nielsen, R. K. (2015). Introduction: The Uncertain Future of Local Journalism. In Nielsen, R.K. (Ed) Local Journalism. The decline of newspapers and the rise of digital media (4-7). London, New Yourk: I.B. TAURIS.

Richards, I. (2012). Beyond city limits: Regional journalism and social capital. Journalism 14, 628-638.

The Mass Media Policy Guidelines of Latvia 2016-2020. (2016). Available: https://www.km.gov.lv/uploads/ckeditor/files/EN/media_policy/Mass\%20Media\%20Po licy\%20Guidelines\%20of\%20Latvia\%202016-2020.pdf

Tuan, Y. F. (1979). Space and place: humanistic perspective. In: Gale S., Olsson, G. (Eds) Philosophy in Geography (415-416). London: D. Reidel.

Zhang, I. (2017). Bounding and bonding community: Ethnic diversity and the ethic of inclusion in hyperlocal news. Journalism, 1, 3-4.

Zukin, S. (2009). Naked City: The Death and Life of Authentic Urban Places. Oxford: Oxford University Press. 